\title{
PERBEDAAN PENGARUH PEMBELAJARAN LOMPAT JAUH TERHADAP HASIL BELAJAR LOMPAT JAUH GAYA JONGKOK PADA SISWI PUTRI KELAS III SEKOLAH DASAR
}

\author{
Titin Kuntum Mandalawati \\ Prodi PGSD FIP IKIP PGRI MADIUN \\ titinmandalawati@yahoo.com
}

\begin{abstract}
The purpose of this study was to determine differences in effect learning to use tools long jump rope and circle as high stimulation and distance gradually towards results learn long jump squat style. This study used an experimental method. Experiment by using pre and post test. The study consisted of two groups: tools strap (A) and the group as a circle high stimulation (B). This study population is third grade Elementary School 1 Panggung Barat Magetan 2015. The average results of the study group pretest tools strap (A) amounted to 84.1 and group as circle high stimulation 82.4 (B), initial conditions showed two groups with similar capabilities. The average post test group tools strap (A) amounted to 156.8 and the group as a circle high stimulation 151.4 (B). Based on the results obtained the following conclusions there is a significant difference between the long jump learning using 2 tools and circle as high stimulation and distance gradually towards learning outcomes long jump squat style on third grade Elementary School 1 Panggung Barat Magetan 2012/2013. By p $(0.034<0.05)$. Long jump teaching methods using tools ropes with better results.
\end{abstract}

Keywords: Learning the long jump, long jump squat style

Abstrak

Tujuan penelitian ini untuk mengetahui perbedaan pengaruh pembelajaran lompat jauh menggunakan alat bantu tali dan lingkaran sebagai rangsangan tinggi dan jarak secara bertahap terhadap hasil belajar lompat jauh gaya jongkok Penelitian ini menggunakan metode eksperimen. Eksperimen dengan menggunakan pre and post test. Penelitian terdiri dari 2 kelompok yaitu kelompok alat bantu tali (A) dan kelompok lingkaran sebagai rangsangan tinggi (B). Populasi penelitian ini adalah siswi putri kelas III SD Negeri 1 Panggung Barat Magetan tahun 2015. Hasil penelitian rata-rata pre test kelompok alat bantu tali (A) sebesar 84,1dan kelompok lingkaran sebagai rangsangan tinggi 82,4, kondisi awal menunjukkan kedua kelompok dengan kemampuan setara. ratarata post test kelompok alat bantu tali (A) sebesar 156,8 dan kelompok lingkaran sebagai rangsangan tinggi 151,4. Berdasarkan hasil penelitian diperoleh simpulan sebagai berikut ada perbedaan pengaruh yang signifikan antara pembelajaran lompat jauh menggunakan alat bantu tali dan lingkaran sebagai rangsangan tiggi dan jarak bertahap terhadap hasil belajar lompat jauh gaya jongkok pada siswi putri kelas III SD Negeri 1 Panggung Barat Magetan tahun pelajaran 2012/2013. Dengan p $(0,034<0,05)$. Metode pembelajaran lompat jauh menggunakan alat bantu tali dengan hasil yang lebih baik.

Kata Kunci : Pembelajaran lompat jauh, lompat jauh gaya jongkok 


\section{A. Pendahuluan}

Pendidikan

merupakan suatu proses pembelajaran melalui aktivitas jasmani yang didesain untuk meningkatkan kebugaran jasmani, mengembangkan ketrampilan motorik, pengetahuan dan perilaku hidup sehat dan aktif, sikap sportif dan kecerdasan emosi. Tujuan yang ingin dicapai melalui pendidikan jasmani mencakup pengembangan individu secara menyeluruh. Artinya, cakupan pendidikan jasmani tidak hanya pada aspek jasmani saja tetapi juga aspek mental, emosional, sosial, dan spiritual.

Pendidikan jasmani dan kesehatan yang diajarkan di sekolah memiliki peranan sangat penting yaitu, memberikan kesempatan kepada peserta didik untuk terlibat langsung dalam berbagai pengalaman belajar melalui aktivitas jasmani, olahraga dan kesehatan yang terpilih yang dilakukan secara sistematis. Pembekalan pengalaman belajar itu diarahkan untuk membina pertumbuhan fisik dan pengembangan psikis yang lebih baik, sekaligus membentuk pola hidup sehat dan bugar sepanjang hayat.

Pelaksanaan pembelajaran pendidikan jasmani didalamnya diajarkan beberapa macam cabang olahraga yang terangkum kurikulum pendidikan jasmani.
Salah satu cabang olahraga yang diajarkan dalam pendidikan jasmani yaitu atletik. Atletik merupakan induk dari semua cabang olahraga yang diajarkan dari sekolah tingkat paling rendah (SD) bahkan Perguruan Tinggi (PT). Seperti dikemukakan Yoyo Bahagia, Ucup Yusuf dan Adang Suherman (1999/ 2000: 1) bahwa, "atletik merupakan salah satu mata pelajaran pendidikan jasmani kepada siswi dari Sekolah Dasar (SD), Sekolah Lanjutan Tingkat Pertama (SMP) dan Sekolah Lanjutan Tingkat Atas (SLTA)".

Seorang guru pendidikan jasmani dan kesehatan untuk mencapai tujuan pembelajaran atletik, harus memperhatikan perkembangan anak, karakteristik anak, kemampuan anak dan kesukaan anak serta tujuan yang harus di capai. Cabang olahraga atletik didalamnya terdiri dari empat nomor utama yaitu jalan, lompat, lari dan lempar. Dari setiap nomor tersebut didalamnya terdapat beberapa nomor yang diperlombakan. Untuk nomor lari terdiri atas: lari jarak pendek, jarak menengah, jarak jauh atau marathon, lari gawang, lari sambung, dan lari cross country. Nomor lompat meliputi: lompat jauh, lompat tinggi, lompat jangkit, lompat tinggi galah. Nomor lempar meliputi lempar cakram, lempar lembing, tolak peluru dan lontar martil.

Berkaitan dengan nomor-nomor atletik, penelitian ini akan mengkaji dan meneliti nomor lompat khususnya lompat jauh gaya jongkok. Lompat jauh gaya jongkok merupakan suatu 
rangkaian gerakan yang diawali dengan berlari, menumpu untuk menolak, melayang di udara dengan sikap jongkok dan mendarat sejauh-jauhnya. Upaya membelajarkan lompat jauh gaya jongkok pada siswi sekolah perlu diterapkan cara mengajar yang baik dan tepat. Hal ini karena, para siswi pada umumnya belum menguasai teknik lompat jauh gaya jongkok, bahkan para siswi kurang senang dengan pembelajaran atletik.

Anak tidak pada tempatnya bila mereka dilatih untuk mencapai prestasi tinggi dalam olahraga tetapi sebaliknya mereka harus dibimbing sesuai dengan kemampuannya. Dalam pengajaran pendidikan jasmani di sekolah dasar harus disesuaikan dengan tingkat kemampuan siswi baik ditinjau dari segi fisik maupun ditinjau dari segi mental.

Berdasarkan observasi dibeberapa SD di kecamatan Barat kabupaten Magetan pada tahun 2014, dapat diketahui bahwa masih banyak guru pendidikan jasmani kesehatan dan rekreasi di dalam pembelajaran atletik cenderung pada penguasaan teknik dan prestasi, sehingga banyak siswi SD yang tidak berminat atau tidak tertarik pada cabang olahraga atletik tersebut. Akibat tidak berminat dan kurang tertarik banyak siswi enggan untuk mengikuti.
Selanjutnya menurut Djumidar (2007: 11.31) "dunia anak lebih dekat dengan situasi permainan dari pada yang serius, di dalam pembelajaran disajikan banyak variasi-variasi agar supaya tidak mudah jenuh sebab siswi kerap kali juga cepat bosan melaksanakan kegiatannya".

Model pendekatan bermain, dimaksudkan untuk mengembangkan aspek-aspek kemampuan motorik melalui aktivitas bermain yang variatif, berjenjang tingkat kesulitannya. Permainan atletik merupakan kombinasi antara kegembiraan gerak dan tantangan tugas gerak yang dekat dengan pengalaman nyata. Dengan demikian guru dapat memanfaatkan pendekatan bermain ini untuk memotivasi siswi melakukan lompat jauh gaya jongkok dengan memberikan materi yang merangsang untuk bermain, yaitu menggunakan tali sebagai rangsangan tinggi dan lingkaran sebagai rangsangan jarak.

Pembelajaran lompat jauh menggunakan alat bantu tali dan lingkaran sebagai rangsangan tinggi dan jarak merupakan bentuk pembelajaran lompat jauh yang bertujuan untuk merangsang siswi agar mampu melompat sejauh-jauhnya. Namun dari kedua bentuk pembelajaran tersebut belum diketahui efektivitasnya, karena masing-masing pembelajaran tersebut memiliki kelebihan dan kelemahan, sehingga belum diketahui pembelajaran mana yang lebih baik pengaruhnya terhadap hasil belajar lompat jauh gaya jongkok. 
Pembelajaran lompat jauh menggunakan alat bantu tali dan lingkaran sebagai rangsangan tinggi dan jarak bertujuan meningkatan pencapaian lompatan yang sejauh-jauhnya. Di sisi lain juga bertujuan untuk mengembangkan penguasaan teknik lompat jauh gaya jongkok. Namun demikian, lompatan dapat dicapai sejauh-jauhnya tidak hanya dipengaruhi pembelajaran yang baik dan terprogram tetapi juga kecepatan merupakan unsur penting dalam lompat jauh seperti yang diungkapkan Soedarminto (2004; 6.5) "pada lompat jauh, kecepatan awalan meupakan faktor yang penting guna mengembangkan daya pada waktu bertolak'.

\section{B. Metode penelitian}

Penelitian ini akan dilaksanakan di Lapangan Desa Panggung Barat Magetan. Penelitian dilaksanakan selama satu setengah bulan pada bulan pebruari 2015 sampai dengan maret 2015, dengan frekuensi latihan tiga kali dalam satu minggu. Metode yang digunakan dalam penelitian ini adalah metode eksperimen. Dasar penggunaan metode ini adalah kegiatan percobaan yang diawali dengan mememberikan perlakuan kepada subyek yang diakhiri dengan suatu tes guna mengetahui pengaru perlakuan yang telah diberikan. Sugiyanto (1994:21) menyatakan
"Tujuan penelitian eksperimental adalah untuk meneliti ada tidaknya hubungan sebab akibat serta besarnya hubungan sebab akibat tersebut dengan cara memberikan perlakuan (treatment) terhadap kelompok eksperimen yang hasilnya dibandingkan dengan hasil kelompok kontrol yang tidak diberikan perlakuan atau diberi perlakukan yang berbeda". Rancangan penelitian yang digunakan adalah pre and post test with control design Sugiyanto (1994 : 30). Rancangan ini menggunakan 2 kelompok, yaitu kelompok alat bantu tali (A) dan kelompok lingkaran sebagai rangsangan tinggi. Dengan rancangan ini bisa diteliti pengaruh setiap variabel independen terhadap variabel dependen, dan juga pengaruh interaksi antara variabel-variabel. Dalam hal ini populasi dalam penelitian adalah siswi putri kelas III SD Negeri I Panggung Barat Magetan tahun pelajaran 2015 yang berjumlah 30 orang.

Memberikan treatment atau perlakuan harus dipertimbangkan secara benar-benar. Hal ini bertujuan agar tidak terjadi kelelahan yang berlebihan akibat dari frekuensi pembelajaran yang terlalu padat atau program pembelajaran yang terlalau padat atau program pembelajaran itu kurang berhasil karena frekuensinya kurang. Pembelajaran dalam peneletian ini dilakukan dengan frekuensi 3 kali seminggu selama 6 minggu. Dengan pembelajaran 3 kali seminggu selama 6 minggu diharapkan sudah terdapat peningkatan kemampuan lompat jauh gaya jongkok (2004: 3.6). Pengukuran data dengan menggunakan 
metode test. Analisa data meliputi: uji kesetaraan untuk menetukan agar kedua kelompok mempunyai kemampuan yang sama sebelum dilakukan treatment, uji normalitas data, uji homogenitas dan uji $\mathrm{t}$ tidak berpasangan.

\section{Pelaksanaan Pembelajaran}

Lompat Jauh Gaya Jongkok Menggunakan Tali Sebagai Rangsangan Tinggi Bertahap

Lompat jauh merupakan rangkaian gerakan yang diawali dengan lari cepat, menolak, melayang dan mendarat. Gerakangerakan dalam lompat jauh tersebut harus dilakukan secara baik dan harmonis tidak diputusputus pelaksanaannya agar diperoleh lompatan sejauhjauhnya. Seperti dikemukakan Aip Syarifuddin (1992: 90) bahwa, "Lompat jauh adalah suatu bentuk gerakan melompat mengangkat kaki ke atas ke depan dalam upaya membawa titik berat badan selama mungkin di udara (melayang di udara) yang dilakukan dengan cepat dan dengan jalan melalui tolakan pada satu kaki untuk mencapai jarak yang sejauhjauhnya".

Lompat jauh gaya jongkok disebut juga gaya duduk di udara (sit down in the air). Dikatakan gaya jongkok karena gerakan yang dilakukan pada saat melayang di udara membentuk sikap seperti orang jongkok atau duduk. Gerakan jongkok atau duduk ini terlihat saat membungkukkan badan dan kedua lutut ditekuk, kedua tangan ke depan. Pada saat mendarat kedua kaki dijulurkan ke depan, mendarat dengan bagian tumit lebih dahulu dan kedua tangan ke depan. Untuk menghindari kesalahan saat mendarat, maka diikuti dengan menjatuhkan badan ke depan.

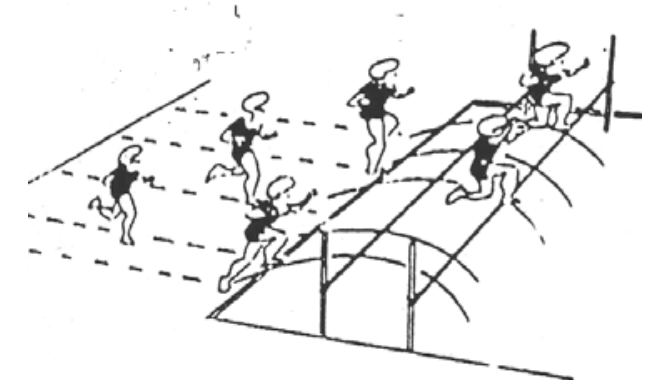

Gambar 2. Pembelajaran Lompat Jauh Gaya Jongkok Menggunakan Tali (Djumidar, 2007:6.16)

2. Pelaksanaan Pembelajaran Lompat Jauh Gaya Jongkok Menggunakan Lingkaran sebagai Rangsangan Jarak Bertahap

Prinsipnya pembelajaran lompat jauh gaya jongkok menggunakan lingkaran sama dengan pembelajaran lompat jauh gaya jongkok menggunakan tali. Perbedaannya terletak pada alat yang digunakan yaitu dengan lingkaran karet (ban). Lingkaran karet tersebut dimaksudkan untuk melatih kecermatan dalam mengatur tempo irama kecepatan, sehingga dapat mendarat dengan baik di tengah-tengah lingkaran”. Di samping itu juga untuk merangsang lompatan yang sejauh-jauhnya. Seperti dikemukakan Djumidar (2007: 6.17) bahwa, "Tujuan pembelajaran lompat jauh menggunakan lingkaran karet yaitu melatih kecermatan dalam mengatur 
tempo/kecepatan hingga kedua kaki mampu mendarat di lingkaran tersebut".

Pelaksanaan pembelajaran lompat jauh menggunakan lingkaran yaitu, lingkaran karet ditata sedemikian rupa. Lingkaran karet ditata dengan jarak yang beragam. Siswi melakukan awalan, untuk selanjutnya menumpu dan menolak serta mendarat pada lingkaran yang mereka anggap mampu, darai lingkaran-lingkaran yang ditata beragam tersebut. Pendaratan harus tepat di tengahtengah lingkaran. Berikut ini disajikan ilustrasi pembelajaran lompat jauh menggunakan lingkaran sebagai berikut:

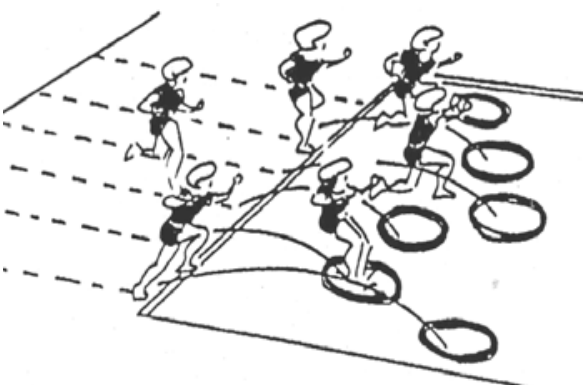

Gambar 3. Pembelajaran Lompat Gaya Jongkok Menggunakan Lingkaran (Djumidar, 2007: 6.17)

\section{Hasil penelitian}

Hasil belajar lompat jauh gaya jongkok untuk kelompok A (tali) dan kelompok B (lingkaran) dapat dilihat pada tabel 1 berikut.

Tabel 1. Hasil Belajar Lompat Jauh Gaya Jongkok

\begin{tabular}{|c|c|c|c|c|c|}
\hline \multirow[b]{2}{*}{ Kelompok } & \multicolumn{2}{|c|}{ Pre Test } & \multicolumn{2}{|c|}{ Pos Test } & \multirow{2}{*}{$\begin{array}{c}\text { Rata-rata } \\
\text { peningkatan setelah } \\
\text { eksperimen }\end{array}$} \\
\hline & Rata-rata & $\begin{array}{c}\text { Hasil Uji t } \\
\text { awal }\end{array}$ & $\begin{array}{c}\text { Rata- } \\
\text { rata }\end{array}$ & $\begin{array}{l}\text { Hasil uji t } \\
\text { akhir }\end{array}$ & \\
\hline $\begin{array}{c}\text { Kelompok } \\
\text { Tali (A) }\end{array}$ & 84,1 & \multirow{2}{*}{$\begin{array}{c}\text { t hitung } \\
0,959(\mathrm{p} \\
0,515> \\
0,05)\end{array}$} & 156,8 & \multirow{2}{*}{$\begin{array}{c}\text { t hitung } \\
2,233(\mathrm{p} \\
0,034< \\
0,05)\end{array}$} & 72,7 \\
\hline $\begin{array}{c}\text { Kelompok } \\
\text { Lingkaran (B) }\end{array}$ & 82,4 & & 151,4 & & 69,0 \\
\hline
\end{tabular}

Hasil penelitian pada tabel di atas menunjukkan rata-rata pre test kelompok alat bantu tali (A) sebesar 84,1dan kelompok lingkaran sebagai rangsangan tinggi 82,4, kondisi awal menunjukkan kedua kelompok dengan kemampuan setara. Ratarata post test kelompok alat bantu tali (A) sebesar 156,8 dan kelompok lingkaran sebagai rangsangan tinggi 151,4 hal ini menunjukkan pada kelompok metode pembelaran menggunakan tali dengan hasil atau peningkatan yang lebih baik. Rata-rata kelompok alat bantu tali (A) mengalami kenaikan 72,7 cm, sedangkan pada kelompok lingkaran sebagai rangsangan tinggi rata-rata peningkatan $69 \mathrm{~cm}$. Haisl uji didapatkan $\mathrm{t}$ hitung sebesar 2,233 dan angka signifikan ( $p$ value) $0,034<0,05$ yang menunjukkan ada perbedaan pengaruh yang signifikan antara pembelajaran lompat jauh 
menggunakan alat bantu tali dan lingkaran sebagai rangsangan tiggi dan jarak bertahap terhadap hasil belajar lompat jauh gaya jongkok pada siswi putri kelas III SD Negeri 1 Panggung Barat Magetan tahun 2015.

\section{Pembahasan}

Penelitian ini merupakan penelitian kuantitatif mempunyai tujuan untuk mengetahui perbedaan pengaruh pembelajaran lompat jauh menggunakan alat bantu tali dan lingkaran sebagai rangsangan tinggi dan jarak secara bertahap terhadap hasil belajar lompat jauh gaya jongkok pada siswi putri kelas III SD Negeri 1 Panggung Barat Magetan tahun 2015. Pada kelompok siswi yang diberi perlakuan pembelajaran lompat jauh menggunakan tali mempunyai peningkatan yang lebih baik terhadap kemampuan lompat jauh gaya jongkok dibandingkan dengan kelompok siswi yang diberi perlakuan pembelajaran lompat jauh menggunakan lingkaran. Hal ini karena, siswi dituntut untuk melompati tali yang dibentangkan dengan ketinggian tertentu, sehingga lompatan harus dilakukan setinggi mungkin agar tidak menyentuh atau menabrak tali tersebut. Lompatan yang tinggi akan dapat mendukung penguasan teknik melayang yaitu untuk membuat posisi jongkok. Namun sebaliknya, pada pembelajaran lompat jauh gaya jongkok menggunakan lingkaran ada kecenderungan untuk melompat sejauh-jauhnya dan teknik melayang di udara sedikit terabaikan.

Pembelajaran lompat jauh gaya jongkok menggunakan tali merupakan bentuk pembelajaran yang mengarah pada pengembangan teknik melayang di udara. Hal ini karena, pada umumnya siswi kurang mampu melakukan lompatan yang tinggi. Para siswi pada umumnya dalam melakukan lompat ke depan, tidak melompat tinggi jauh ke depan. Lompatan yang kurang tinggi akan mengakibatkan badan akan lebih cepat mendarat, sehingga lompatannya tidak maksimal. Untuk meningkatan lompatan yang tinggi, maka perlu diciptakan kondisi belajar yang dapat merangsang lompatan yang tinggi diantaranya dengan menggunakan tali. Pembelajaran lompat jauh gaya jongkok menggunakan tali tersebut dapat merangsang gerakan melompat yang lebih tinggi, karena adanya tali yang harus dilompati, sehingga akan diperoleh lompatan yang jauh. Dengan adanya tali yang harus dilompati dapat merangsang gerakan siswi untuk membuat posisi jongkok, sehingga unsur teknik melayang di udara dapat dikembangkan.

\section{E. Simpulan dan saran}

\section{Simpulan}

1. Nilai rata-rata hasil akhir kelompok alat bantu tali sebesar $156,8 \mathrm{~cm}$ dan nilai rata-rata hasil akhir kelompok alat bantu lingkaran sebagai 
rangsangan tiggi dan jarak bertahap sebesar $151,4 \mathrm{~cm}$

2. Ada perbedaan pengaruh pembelajaran lompat jauh menggunakan alat bantu tali dan lingkaran sebagai rangsangan tiggi dan jarak bertahap terhadap hasil belajar lompat jauh gaya jongkok pada siswi putri kelas 4 dan 5 SD Negeri 1 Panggung Barat Magetan tahun 2015. (p 0,034 $<0,05)$. Metode pembelajaran menggunakan alat bantu tali lebih baik daripada menggunakan alat bantu lingkaran dengan rata-rata peningkatanya $72,7 \mathrm{~cm}$ dan 69,0 .

\section{Saran}

1. Untuk meningkatkan kemampuan lompat jauh gaya jongkok dapat digunakan alat bantu tali dan lingkaran sebagai rangsangan tinggi dan jarak. Dari hasil penelitian ini menunjukkan bahwa, penggunaan alat bantu tali lebih baik pengaruhnya terhadap peningkatan kemampuan lompat jauh gaya jongkok, sehingga penggunaan alat bantu tali dapat digunakan untuk meningkatkan kemampuan lompat jauh gaya jongkok.

2. Dalam usaha meningkatkan kemampuan lompat jauh gaya jongkok, disamping menggunakan alat bantu yang tepat harus memperhatikan tingkat kecepatan lari siswi. Tingkat kecepatan lari siswi harus menjadi pertimbangan dalam latihan, karena tingkat kecepatan lari akan berpegaruh terhadap kemampuan lompat jauh gaya jongkok.

\section{DAFTAR PUSTAKA}

A. Hamid. 1993.Teori dan Praktek Atletik. Surakarta: UNS Press.

Aip Syarifuddin. 1992. Atletik. Jakarta:

Departemen Pendidikan dan Kebudayaan. Direktorat Jenderal Pendidikan Tinggi. Proyek Pembinaan Tenaga Kependidikan.

Andi Suhendro. 2004. Dasar-dasar Kepelatihan. Jakarta: Universitas Terbuka.

Djumidar. 2004. Dasar-dasar Atletik. Jakarta. Universitas Terbuka.

H.J. Gino, Suwarni, Suripto, Maryanto dan Sutijan. 1998. Belajar dan Pembelajaran II. Surakarta: UNS Press.

Rusli Lutan.1999/2000. Strategi Belajar Mengajar Penjaskes. Semarang: Depdikbud. Direktorat Jendral Pendidikan Dasar dan Menengah.

Rusli Lutan. 1988. Belajar Ketrampilan Motorik Pengantar Teori dan Metode. Jakarta: Depdikbud. Dirjendikti.

Sudjana. 1994. Metoda Statistika. Bandung: Tarsito.

Sugiyanto. 1995. Metodologi Penelitian. Surakarta: UNS Press. 
176 | Premiere Educandum, Volume 5 Nomor 2, Desember 2015, 168 - 176

Sukintaka. 1992. Teori Bermain untuk D2 PGSD Penjaskes. Bandung: Depdikbud. Direktorat jendral Pendidikan Tinggi Proyek Pembinaan Tenaga Kependidikan.

Yudha M. Saputri. 2001. Dasardasar Ketrampilan Atletik. Jakarta: Direktorat Jendral Olahraga.
Yoyo Bahagia, Ucup Yusuf dan Adang Suherman. 1999/2000. Atletik. Depdikbud. Direktorat Jenderal Pendidikan Dasar dan Menengah Bagian Proyek Penataran Guru SMP Setara DIII. 